\title{
ARID1B: From the Garden of Eden to the Sahara
}

\author{
Jules Lin, MD, FACS
}

\footnotetext{
From the Section of Thoracic Surgery, Department of Surgery, University of Michigan Medical Center, Ann Arbor, Mich.

Disclosures: Author has nothing to disclose with regard to commercial support.

Received for publication Jan 21, 2018; accepted for publication Jan 30, 2018; available ahead of print March 8 , 2018.

Address for reprints: Jules Lin, MD, FACS, Section of Thoracic Surgery, University of Michigan Medical Center, 1500 E Medical Center Dr, 2120TC/5344, Ann Arbor, MI 48109-5344 (E-mail: juleslin@umich.edu).

J Thorac Cardiovasc Surg 2018;155:e193-4

$0022-5223 / \$ 36.00$

Copyright (C) 2018 by The American Association for Thoracic Surgery

https://doi.org/10.1016/j.jtcvs.2018.01.058
}

In the case report by $\mathrm{Su}$ and colleagues ${ }^{1}$ in this issue of the Journal, a shared mutation in the AT-rich interaction domain 1B gene (ARIDIB), a component of the switch/sucrose nonfermentable (SWI/SNF) chromatin remodeling complex frequently mutated in cancers, was identified in multiple lung lesions from a single patient. $\mathrm{Su}$ and colleagues ${ }^{1}$ conclude that $A R I D 1 B$ plays a significant role in lung cancer formation; however, further work will be needed to determine whether ARID1B is a key cancer driver in lung cancer.

Mutations and deletions of different subunits of the SWI/ SNF complex occur in approximately $20 \%$ of human cancers. ARIDIB mutations have been described in neuroblastoma, pancreatic, gastric, and papillary thyroid cancers. Huang and associates ${ }^{2}$ found the complex to be mutated in $35.12 \%$ of lung carcinomas, second only to TP53, and concluded that loss of SWI/SNF chromatin remodeling genes resulted in genomic instability in lung cancer. Yoshimoto and coworkers ${ }^{3}$ reported loss of expression of $A R I D 1 A, A R I D I B$, and BAF47 in a subset of non--small cell lung carcinomas, although this was more frequent in large cell and pleomorphic lung cancers $(26.3 \%)$ than in squamous cell or adenocarcinomas $(8.4 \%)$ as described by $\mathrm{Su}$ and colleagues ${ }^{1}$ The loss of the SWI/SNF complex has been associated with dedifferentiation in lung and other cancers, and although $A R I D I B$ mutations have been associated with aggressive tumors and poor survival in other studies, it is interesting that only 1 of the 4 lung lesions analyzed in this case report was invasive moderately differentiated adenocarcinoma, whereas 2 were early-stage adenocarcinoma in situ and 1 was a precancerous atypical adenomatous hyperplasia.

To understand the significance of this $A R I D I B$ mutation, it is important to evaluate the expression of ARID1B protein, along with other components of the SWI/SNF complex. The ARIDIA gene is more commonly mutated in other cancers, and Kelso and associates ${ }^{4}$ found that loss of ARIDIA in colon cancer cells resulted in significant changes in chromatin accessibility, whereas knockdown of the $A R I D 1 B$ gene alone in wild-type cells had no effect. $A R I D I B$ knockdown was only apparent in the setting of mation of cancer.

\section{References} 2018;155:e185-91. Rep. 2015;33:283-91.

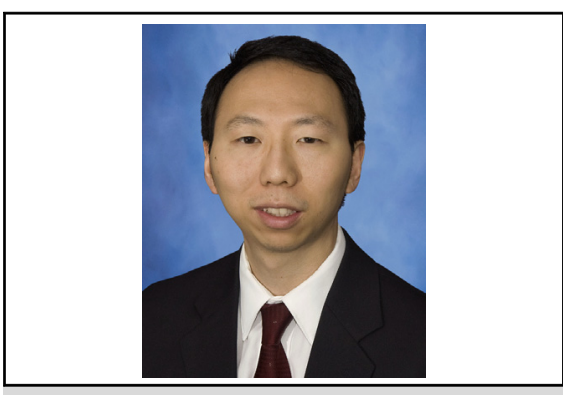

Jules Lin, MD, FACS

Central Message

Further work is necessary to determine the importance of a shared $A R I D I B$ mutation, found in multiple lung lesions in a single patient, which may contribute to genomic instability in lung cancer.

See Article page e185.

ARIDIA mutations. Both mutations are frequently present and have a functional dependence on each other in the for-

The interaction between SWI/SNF subunit mutations and other genetic changes could also be crucial. This patient had an additional germline epidermal growth factor receptor gene $(E G F R)$ mutation. The SWI/SNF complex regulates EGFR signaling during development, and the loss of SMARCA4, a component of the SWI/SNF complex, increases $E G F R$ expression in lung cancers. ${ }^{6}$ This raises the possibility that targeting $E G F R$ may be an effective strategy in SWI/SNF mutant cancers, because the loss of tumor suppressors is difficult to target.

$A R I D 1 B$ mutation may be an early change in lung cancer, altering the SWI/SNF chromatin remodeling complex, contributing to overall genomic instability, and allowing a multitude of heterogeneous genetic changes to accumulate as lung cancer progresses. Further work is necessary to determine the importance of this shared $A R I D 1 B$ mutation in lung cancer and whether it is truly the fruit from the tree of life, a cancer driver allowing cells to become immortal, transforming pink healthy lung from the Garden of Eden to the Sahara, an arid desert wasteland of cancer nodules.

1. Su K, Gao S, Ying J, Zou S, He J. Sequencing a super multiple synchronous lung cancer reveals a novel variant in driver gene ARIDIB. J Thorac Cardiovasc Surg.

2. Huang HT, Chen SM, Pan LB, Yao J, Ma HT. Loss of function of SWI/SNF chromatin remodeling genes leads to genome instability of human lung cancer. Onco 
3. Yoshimoto T, Matsubara D, Nakano T, Tamura T, Endo S, Sugiyama Y, et al. Frequent loss of the expression of multiple subunits of the SWI/SNF complex in large cell carcinoma and pleomorphic carcinoma of the lung. Pathol Int. 2015; 65:595-602.

4. Kelso TW, Porter DK, Amaral ML, Shokhirev MN, Benner C, Hargreaves DC. Chromatin accessibility underlies synthetic lethality of SWI/SNF subunits in ARID1A-mutant cancers. Elife. 2017;6: https://doi.org/10.7554/eLife.30506.
5. Helming KC, Wang X, Wilson BG, Vazquez F, Haswell JR, Manchester HE, et al. ARID1B is a specific vulnerability in ARIDIA-mutant cancers. Nat Med. 2014;20: 251-4.

6. Fillmore CM, Xu C, Desai PT, Berry JM, Rowbotham SP, Lin YJ, et al. EZH2 inhibition sensitizes BRG1 and EGFR mutant lung tumours to TopoII inhibitors. $\mathrm{Na}$ ture. 2015;520:239-42. 